\title{
Endotracheal cuff pressure and tracheal mucosal blood flow: endoscopic study of effects of four large volume cuffs
}

\author{
R D SEEGOBIN, G L VAN HASSELT
}

\begin{abstract}
Large volume, low pressure endotracheal tube cuffs are claimed to have less deleterious effect on tracheal mucosa than high pressure, low volume cuffs. Low pressure cuffs, however, may easily be overinflated to yield pressures that will exceed capillary perfusion pressure. Various large volume cuffed endotracheal tubes were studied, including Portex Profile, Searle Sensiv, Mallinkrodt Hi-Lo, and Lanz. Tracheal mucosal blood flow in 40 patients undergoing surgery was assessed using an endoscopic photographic technique while varying the cuff inflation pressure. It was found that these cuffs when overpressurised impaired mucosal blood flow.

This impairment of tracheal mucosal blood flow is an important factor in tracheal morbidity associated with intubation. Hence it is recommended that a cuff inflation pressure of $30 \mathrm{~cm} \mathrm{H}_{2} \mathrm{O}(22 \mathrm{~mm} \mathrm{Hg})$ should not be exceeded.
\end{abstract}

\section{Introduction}

The recognition of complications associated with endotracheal tubes with high pressure, low volume cuffs has resulted in wide acceptance of large volume, low pressure cuffs for patients requiring prolonged ventilation. Tracheal morbidity has been assessed with both types of cuffed endotracheal tubes by histological techniques. Lateral wall pressure may be the most important factor contributing to the morbidity of intubation.

The physical principles and characteristics of large volume cuffs $^{1}$ have been described using in vitro models ${ }^{2-5}$ and in vivo. ${ }^{2}$

\footnotetext{
Shackleton Department of Anaesthetics, Southampton General Hospital, Shirley, Southampton SO9 4XY

R D SEEGOBIN, MRCP, FFARCS, senior registrar

$G$ L VAN HASSELT, FFARCS, senior registrar

Correspondence to: Dr R D Seegobin.
}

High volume cuffs may have ideal characteristics in air and can produce clinical seal with low lateral wall pressures. Nevertheless, these cuffs may easily be overinflated, generating excessive lateral wall pressures. ${ }^{4}{ }^{5}$ This effect may also occur with nitrous oxide administration during anaesthesia, the nitrous oxide diffusing into the cuff and creating excessive pressure $^{6} 7$ despite a satisfactory initial sealing pressure.

The effect of lateral wall pressure on mucosal blood flow has been measured indirectly in $\operatorname{dogs}^{8}$ and rabbits. ${ }^{9}$ We can now assess the mucosa macroscopically using fibreoptic bronchoscopes. The trachea is non-pigmented, and it may be possible to visualise blood vessels deep to the mucosa. We report a study designed to assess the effect of intubation and lateral wall pressure on mucosal and tracheal blood flow in man using standard endoscopic techniques and transparent large volume cuffed endotracheal tubes.

\section{Materials and methods}

Four types of $8.5 \mathrm{~mm}$ (internal diameter) large volume cuffs were studied: Portex Profile, Searle Sensiv, Mallinkrodt Hi-Lo, and Lanz endotracheal tubes. The Lanz tube and cuff are transparent. Portex Profile, Searle Sensiv, and Mallinkrodt Hi-Lo tubes, similar to those usually supplied but constructed of transparent tube and cuff materials, were provided by the respective manufacturers. Forty adults undergoing surgery requiring intubation, paralysis, and ventilation gave informed consent and were admitted to the study. Randomisation of the type of endotracheal tube used was achieved using a suitable table of random numbers. The patients received a standard premedication and anaesthetic regimen.

Patients were premedicated with diazepam $10 \mathrm{mg}$ and metoclopramide $10 \mathrm{mg}$ by mouth two hours before operation. Anaesthesia was induced with thiopentone $3.5 \mathrm{mg} / \mathrm{kg}$ and intubation performed three minutes after alcuronium $0.3 \mathrm{mg} / \mathrm{kg}$. Fentanyl $1 \mu \mathrm{g} / \mathrm{kg}$ was given at induction and $0.25 \mu \mathrm{g} / \mathrm{kg}$ at half hour intervals thereafter. Anaesthesia was maintained and ventilation achieved using a Bain coaxial breathing system with a total fresh gas flow of $70 \mathrm{ml}$ nitrous oxide and oxygen per $\mathrm{kg}$ in a $2: 1$ ratio and a Penlon Nuffield ventilator set to give a tidal volume of $10 \mathrm{ml} / \mathrm{kg}$ at a rate of $12 \mathrm{cycles} / \mathrm{min}$. All cuffs were evacuated to negative pressure before intubation. No lubrication jelly was used. Sterile isotonic saline was used to inflate the cuff, thereby minimising light reflection from the inner wall of the cuff and permitting clear photography. The endotracheal cuffs 
were inflated to $25 \mathrm{~cm} \mathrm{H}_{2} \mathrm{O}$ initially, by which point clinical seal had been effected. The Lanz tubes generated a pressure of $27 \pm 2 \mathrm{~cm}$ $\mathrm{H}_{2} \mathrm{O}$ when inflated owing to the intrinsic pressure limiting balloon. Cuff pressure was measured with a Smith aneroid gauge previously calibrated against a water manometer.

After careful extension of the patient's head, photographs were taken of the circumferential cuff-trachea contact area using an Olympus OM2 camera with a Wolf 85-105 mm lens, a Wolf rigid fibreoptic bronchoscope, and an AMI photographic light source (fig 1).

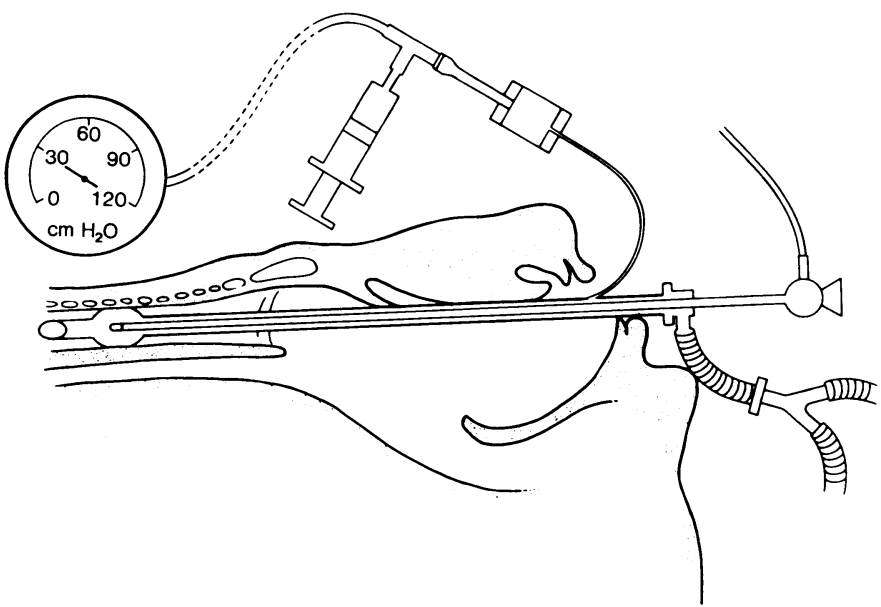

FIG 1-Schematic representation of technique.

Pressures in the Portex Profile, Searle Sensiv, and Mallinkrodt $\mathrm{Hi}-\mathrm{Lo}$ tubes were then increased to $30 \mathrm{~cm} \mathrm{H}_{2} \mathrm{O}$ and thereafter in $10 \mathrm{~cm}$ increments to $100 \mathrm{~cm} \mathrm{H}_{2} \mathrm{O}$. After each rise in cuff pressure the tracheal mucosa-cuff contact area was photographed at zero airway pressure.

During these procedures the patient's blood pressure was measured at two minute intervals using a Bard Sentry automatic blood pressure monitor. All patients were normotensive, the mean arterial pressure being 85 (SD 5) $\mathrm{mm} \mathrm{Hg}$. Endotracheal cuff pressures were then reduced to $30 \mathrm{~cm} \mathrm{H}_{2} \mathrm{O}$ and monitored continuously during anaesthesia. At the end of the operation the cuff-trachea contact area was reexamined and photographed before reversal of the relaxant.

\section{Results}

By using this technique it was possible to assess the mucosa in contact with the endotracheal cuff for alteration in blood flow as judged by the hue of the mucosa, and blood vessels in the submucosa could be visualised.

Figure 2 shows the typical pattern of blood supply to the tracheal mucosa. Anteriorly arterioles run circumferentially in the submucosa in between the tracheal rings with branches crossing the submucosa over the rings; posteriorly arterioles and veins run longitudinally in the submucosa. As the cuff pressure rises the posterior wall becomes

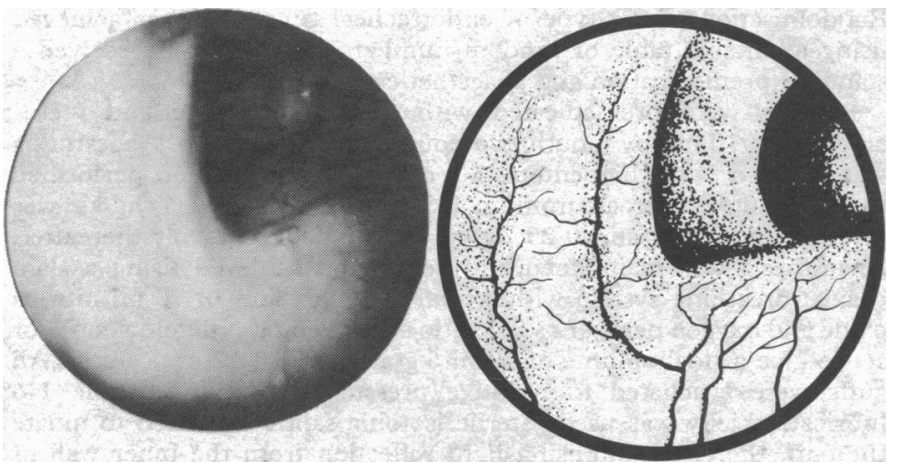

FIG 2-Anatomy of blood flow in tracheal submucosa stretched from its normal flat configuration to accommodate the shape of the inflating cuff. Based on this anatomy the effects of lateral wall pressure on mucosal blood flow can be looked at anteriorly and posteriorly.

The Lanz tubes could not be inflated beyond $27 \mathrm{~cm} \mathrm{H}_{2} \mathrm{O}$ owing to their pressure limiting balloons. The Searle Sensiv, Portex Profile, and Mallinkrodt $\mathrm{Hi}$-Lo tubes could be inflated to intracuff pressure exceeding $100 \mathrm{~cm} \mathrm{H}_{2} \mathrm{O}$. When fully inflated the resting diameters of

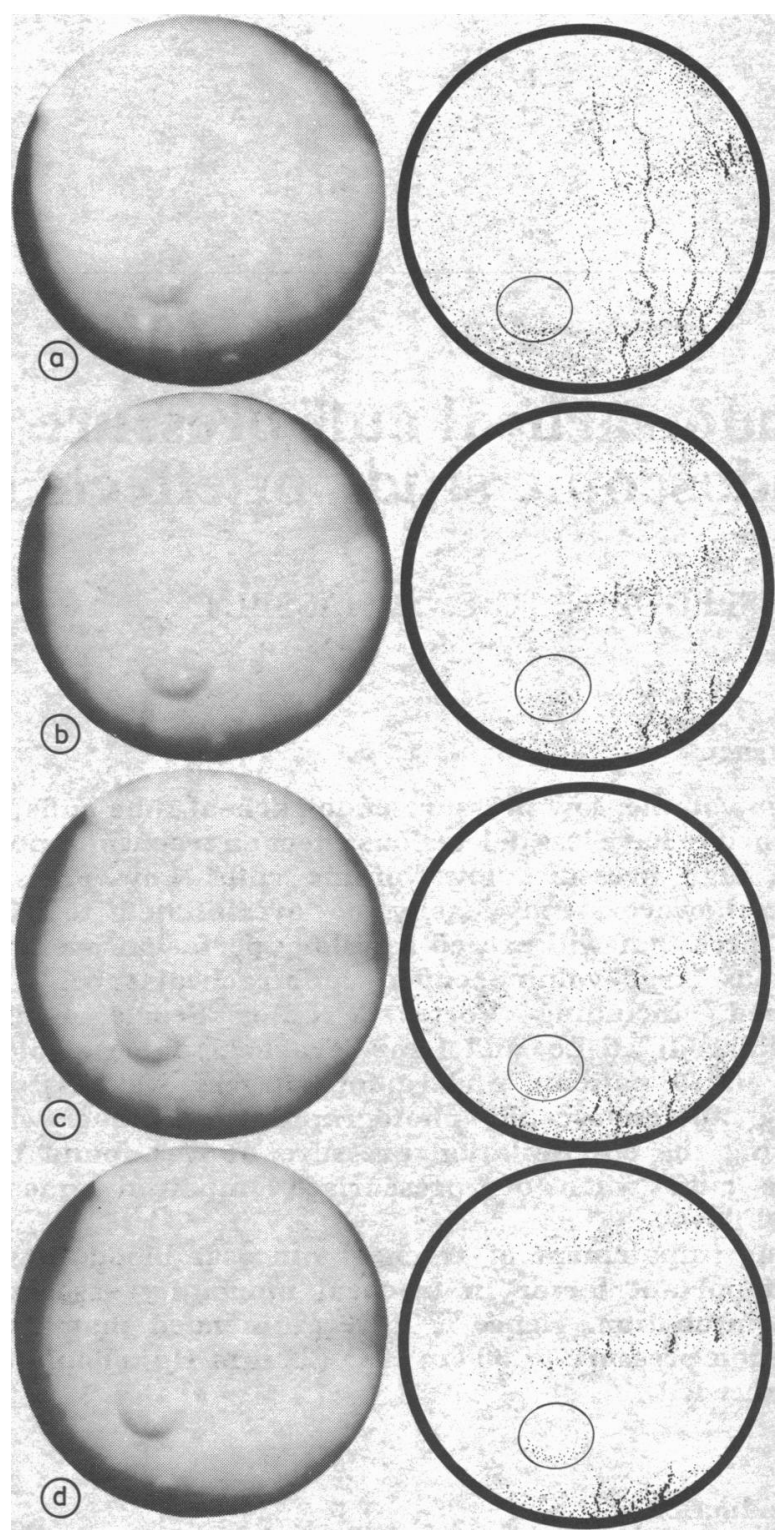

FIG 3-Effect of cuff pressure on mucosal blood flow to anterior tracheal mucosa. (a) $=30 \mathrm{~cm} \mathrm{H} \mathrm{H}_{2} \mathrm{O}$. (b) $=40 \mathrm{~cm} \mathrm{H} \mathrm{H}_{2} \mathrm{O}$. (c) $=50 \mathrm{~cm}$ $\mathrm{H}_{2} \mathrm{O}$. (d) $=100 \mathrm{~cm} \mathrm{H}_{2} \mathrm{O}$.

the Searle Sensiv, Portex Profile, Mallinkrodt Hi-Lo, and Lanz cuffs were $19,28,35$, and $40 \mathrm{~mm}$ respectively. The necessary folding of redundant cuff material created random folds which ran longitudinally and obliquely.

Lanz tubes inflated to a pressure of $27+2 \mathrm{~cm} \mathrm{H}_{2} \mathrm{O}$. Mucosa in all areas of trachea-cuff contact was of a uniform hue. Blood vessels anteriorly and posteriorly were of normal calibre. Numerous folds of redundant cuff material with secretions and air bubbles tracking along them were seen.

Searle Sensiv, Portex Profile, and Mallinkrodt Hi-Lo tubes performed similarly with respect to their effect on tracheal blood flow for a given pressure. All these tubes developed random folds in excess cuff material, being least with Searle Sensiv and most with the Hi-Lo tubes. 
At $25 \mathrm{~cm} \mathrm{H}_{2} \mathrm{O}$-Anteriorly and posteriorly the mucosa was of uniform hue and the blood vessels of normal calibre.

At $30 \mathrm{~cm} \mathrm{H}_{2} \mathrm{O}$-Anteriorly the mucosa over tracheal rings was less pink than in the intercartilagenous areas. Vessels in the submucosa overlying the tracheal rings were of normal calibre. Posteriorly the vessels were of normal calibre and the mucosal hue was similar to that overlying the tracheal rings.

At $40 \mathrm{~cm} \mathrm{H}_{2} \mathrm{O}$-Anteriorly the mucosa over the cartilagenous rings was very pale. Some vessels of reduced calibre could be seen in the submucosa overlying the rings. The mucosa in the intercartilagenous areas retained its normal hue, and the vessels in the submucosa were of normal calibre. Posteriorly the mucosa was pale, and with the stretching of the posterior wall the arterioles in the submucosa became attenuated.

At $50 \mathrm{~cm} \mathrm{H}_{2} \mathrm{O}$-Anteriorly the mucosa overlying the tracheal rings was blanched and no blood vessels could be seen in the submucosa. The intercartilagenous mucosa retained its normal hue. Posteriorly the mucosa was blanched and the vessels in the submucosa were more attenuated.

At $60-100 \mathrm{~cm} \mathrm{H}{ }_{2} \mathrm{O}$-Anteriorly the mucosa overlying the tracheal rings remained blanched, again with no blood vessels visible in the overlying submucosa. The mucosa in the intercartilagenous areas retained its normal hue and the vessels their normal calibre. Posteriorly the vessels became progressively more attenuated, and at $100 \mathrm{~cm} \mathrm{H} \mathrm{H}_{2} \mathrm{O}$ they were visible only intermittently as perfusion pressure exceeded lateral wall pressure.

Even at a pressure of $100 \mathrm{~cm} \mathrm{H} \mathrm{H}_{2} \mathrm{O}$ secretions and air bubbles could be seen trapped within the folds of the cuffs.

Figures 3 and 4 show the typical appearances at the various pressures. The variation in hue anteriorly was represented by a change in stippling pattern. Figure 4 shows the folds, trapped secretions being visible in the upper fold at all pressures.

Before extubation further evaluation of the trachea-cuff contact area proved difficult owing to secretions lining the endotracheal tube. Incidental mucosal haemorrhages were seen but bore no relation to folds. Figure 4 shows one such haemorrhage at 11 o'clock.

Above an intracuff pressure of $30 \mathrm{~cm} \mathrm{H}_{2} \mathrm{O}$ there was evidence of impairment of mucosal blood flow, anteriorly over the tracheal cartilages and posteriorly as the muscular layer became distorted by the shape of the cuff. At $50 \mathrm{~cm} \mathrm{H}_{2} \mathrm{O}$ and over there was total obstruction of blood flow to the mucosa overlying the tracheal rings and to the mucosa overlying the stretched muscular wall posteriorly. The relative sparing of the intercartilagenous mucosa may have been due to stasis or poor cuff-mucosa contact with subsequent reduced lateral wall pressure. Cuff folds were not obliterated by intracuff pressures up to $100 \mathrm{~cm} \mathrm{H}_{2} \mathrm{O}$.

\section{Discussion}

The morbidity associated with cuffed endotracheal intubation is due to factors which include the use of inert materials, tube size, lateral wall pressure, movement, hypotension, local infection, use of steroids, and the duration of intubation. Awareness of the high lateral wall pressure generated by low volume, high pressure cuffs and the inability to deduce lateral wall pressure from intracuff pressure led to the development of large volume cuffs. ${ }^{1}$ These are designed to provide a measurement of lateral wall pressure, this being equal to or less than intracuff pressure, ${ }^{4}$ and to achieve minimal lateral wall pressure by effecting a clinical seal at low intracuff pressures. In the absence of standards the diameters of these cuffs vary from once to twice that of the adult trachea.

Nordin, who assessed damage to intubated rabbits' tracheas histologically, proposed that over and above damage associated with intubation lateral wall pressure was more important in the aetiology of tracheal morbidity than the duration of intubation if this was less than four hours. ${ }^{9}$ Superficial damage occurred within 15 minutes at a lateral wall pressure of $20 \mathrm{~mm} \mathrm{Hg}$ $\left(27 \mathrm{~cm} \mathrm{H}_{2} \mathrm{O}\right.$ ). This damage was not progressive with time. With a lateral wall pressure of $50 \mathrm{~mm} \mathrm{Hg}\left(68 \mathrm{~cm} \mathrm{H}_{2} \mathrm{O}\right)$ there was partial denuding of basement membrane, and again the depth of damage was not progressive with time beyond 15 minutes. At a lateral wall pressure of $100 \mathrm{~mm} \mathrm{Hg}$, however, within 15 minutes damage extended to include the basement membrane and mucosal stroma, and this damage was progressive with time.

Support for lateral wall pressure as a major cause of tracheal mucosal damage came from further studies. Homi et al found no difference in the depth of erosions on histological examination of the trachea of dogs intubated with either large volume cuffed tubes or low volume cuffed tubes inflated to minimal leak. ${ }^{10}$ Loeser et al found a much reduced mean depth of erosion in dogs intubated with large volume cuffed tubes as opposed to high pressure, low volume cuffed tubes inflated to clinical seal for periods of five to seven hours. The area of erosion was significantly greater with the large volume cuff, and the mean maximum depth of erosion was similar with both types of cuff."

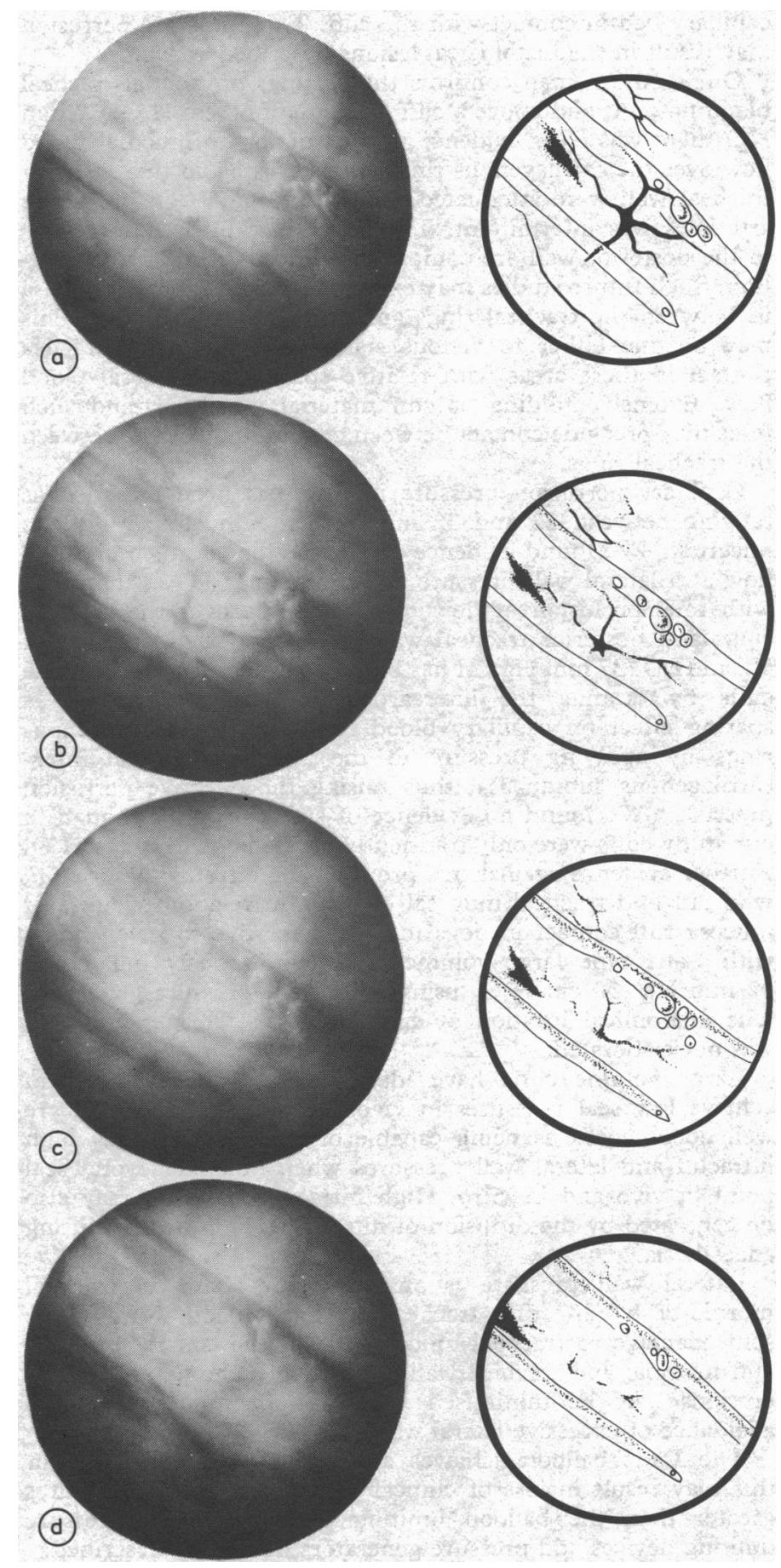

FIG 4-Effect of cuff pressure on arterioles in posterior tracheal submucosa. (a) $=30 \mathrm{~cm} \mathrm{H} \mathrm{H}_{2} \mathrm{O}$. (b) $=40 \mathrm{~cm} \mathrm{H} \mathrm{H}_{2} \mathrm{O}$ (c) $=80 \mathrm{~cm} \mathrm{H} \mathrm{H}_{2} \mathrm{O}$. (d) $=100 \mathrm{~cm} \mathrm{H} \mathrm{H}_{2} \mathrm{O}$. 
The effect of lateral wall pressure on tracheal blood flow has been investigated in dogs and rabbits. Dobrin and Canfield showed a reduction of $40-60 \%$ in tracheal blood flow using thermistor techniques in dogs intubated with low volume, high pressure cuffed tubes. ${ }^{8}$ Reduction in flow was minimal in dogs intubated with large volume cuffs. Nordin showed a system of sinusoidal ectasia in submucosa in rabbits. ${ }^{9}$ His blood flow studies using microsphere techniques showed a tenfold increase in blood flow associated with intubation and before cuff insufflation. Reduction in blood flow to the tracheal mucosa from this tenfold increase was $40 \%$ at a lateral wall pressure of $20-60 \mathrm{~mm} \mathrm{Hg}$. At a lateral wall pressure greater than $60 \mathrm{~mm} \mathrm{Hg}$ blood flow was reduced to $33 \%$ of the initial increase, and at lateral wall pressures exceeding $80 \mathrm{~mm} \mathrm{Hg}$ blood flow was very reduced. The increase in blood flow occurred mainly through the submucosal sinusoids. At cuff pressures exceeding $50 \mathrm{~mm} \mathrm{Hg}$ there was evidence of hindered perfusion of the capillary bed in contact with the cuff. This impaired perfusion may result in the histological lesions described above.

Our study in man confirms the findings on animal tracheal blood flow. At and above a cuff pressure of $50 \mathrm{~cm} \mathrm{H}_{2} \mathrm{O}(37 \mathrm{~mm}$ $\mathrm{Hg}$ ) there was clear evidence of obstruction to mucosal blood flow over the cartilagenous rings. Blood vessels in the posterior tracheal wall were attenuated, and at $100 \mathrm{~cm} \mathrm{H}_{2} \mathrm{O}$ flow along arterioles was intermittent. The depth to which these vessels in the posterior wall are compromised needs further investigation. Such future studies may explain the reason for the mucosa in between the tracheal rings anteriorly remaining pink. This may be due either to venous stasis or to poor cuff-trachea contact in these areas with relative sparing of mucosal blood flow. Extensive folding of cuff material was seen, and such folds may preclude contact between cuff and mucosa in between the tracheal rings.

Capillary perfusion pressure in man has been recorded as ranging between 22 and $32 \mathrm{~mm} \mathrm{Hg}$, and the upper limit is uncertain. We found evidence of obstruction to mucosal blood flow at a lateral wall pressure above $30 \mathrm{~cm} \mathrm{H}_{2} \mathrm{O}(22 \mathrm{~mm} \mathrm{Hg})$, with total occlusion of flow to the mucosa over the tracheal rings and posterior tracheal wall at a lateral wall pressure of $50 \mathrm{~cm} \mathrm{H} \mathrm{H}_{2} \mathrm{O}(37 \mathrm{~mm} \mathrm{Hg})$. It has been proposed that large volume cuffs by draping the intercartilagenous mucosa achieve a sparing effect on capillary blood flow over the cartilagenous rings by applying pressure to the arterioles in the intercartilagenous submucosa, thus raising the effective perfusion pressure. ${ }^{9}$ We found no evidence of such an effect, though in our study cuffs were only transiently inflated above $30 \mathrm{~cm} \mathrm{H}_{2} \mathrm{O}$. Further evidence against this proposal came from Loeser et al, who did find tracheal mucosal erosions in relation to areas of mucosa-cuff contact in dogs intubated for five to seven hours with Lanz type large volume cuffs continuously inflated to $22 \mathrm{~mm} \mathrm{Hg}\left(30 \mathrm{~cm} \mathrm{H}_{2} \mathrm{O}\right)$ using a constant pressure generator. The anatomical location of such mucosal damage, however, was not elaborated.

Large volume cuffs have ideal characteristics in air and achieve low seal pressures in vivo. Such tubes, however, are well documented as being capable of readily generating high intracuff and lateral wall pressures when inflated beyond seal point in vivo and in vitro. High intracuff pressures may also be generated by the diffusion of nitrous oxide into cuffs during anaesthesia.

Lateral wall pressure is an important factor in tracheal morbidity by affecting tracheal capillary blood flow. While some damage to tracheal mucosa due to the contact between cuff material and tracheal wall is inevitable, the depth of such erosions may be minimised by continuous monitoring and avoidance of excessive lateral wall pressures.

The Lanz balloon achieves a pressure limiting effect but this may result in loss of clinical seal with inflating pressures greater than the balloon limiting pressure. Other pressure limiting devices and pressure generators have been described.

We suggest that large volume cuffs without a pressure limiting device should be inflated with a pressure gauge in line to ensure that cuff pressure is maintained within safe limits. The use of sterile isotonic saline during anaesthesia will avoid the rise in intracuff pressure due to the diffusion of nitrous oxide.

In conclusion, while large volume cuffs may achieve clinical seal at low intracuff pressure, inflation beyond this point with small increments of air easily generates excessive intracuff pressure and thus lateral wall pressure. A continuous lateral wall pressure above $30 \mathrm{~cm}$ water $(22 \mathrm{~mm} \mathrm{Hg})$ compromises mucosal capillary blood flow. This flow is totally obstructed by the time lateral wall pressure reaches $50 \mathrm{~cm} \mathrm{H}_{2} \mathrm{O}(37 \mathrm{~mm} \mathrm{Hg})$. This is the most important cause of mucosal damage and is avoidable by careful attention to inflation technique and continuous monitoring of intracuff pressure.

\section{References}

1 Carroll RG, McGinnis GE, Grenvik A. Performance characteristics of tracheal cuffs. Int Anesthesiol Clin 1974;12:111-31.

${ }^{2}$ Crawley BE, Cross DE. Tracheal cuffs. A review and dynamic pressure study. Anaesthesia 1975;30:4-11.

${ }^{3}$ Mackenzie CF, Klose S, Brawn DRG. A study of inflatable cuffs on endotracheal tubes. Brf Anaesth 1976;48:105-9.

4 Black AMS, Seegobin RD. Pressures on endotracheal cuffs. Anaesthesia $1981 ; 36: 498-511$.

${ }^{5}$ Lewis FR, Schlobohm RM, Thomas AW. Prevention of complications from prolonged tracheal intubation. Am f Surg 1978;135:452-7.

6 Stanley TH. Nitrous oxide and pressures and volumes of high and low pressure endotracheal tube cuffs in intubated patients. Anesthesiology $1975 ; 42: 637-40$

${ }^{7}$ Bernhard WN, Yost LC, Turndof H, Cottrell JE, Paegle RD. Physical characteristics of and rates of nitrous oxide diffusion into tracheal tube cuffs. Anesthesiology 1978;48:413-7.

${ }^{8}$ Dobrin P, Canfield T. Cuffed endotracheal tubes: mucosal pressures and tracheal wall blood flow. Am f Surg 1977;133:562-8.

${ }^{9}$ Nordin U. The trachea and cuff induced tracheal injury. An experimental study on causative factors and prevention. Acta Otolaryngol 1976;345, suppl:1-71.

${ }^{10}$ Homi J, Notcutt W, Jones JJ, Sparke BR. A method for comparing endotracheal cuffs. Br $\mathcal{F}$ Anaesth 1978;50:435-45.

"I Loeser EA, Hodges M, Gliedman J, Stanley TH, Johansen RK, Yonetami D. Tracheal pathology following short term intubation with low and high pressure endotracheal tube cuffs. Anesth Analg (Cleve) 1978;57: 577-9.

(Accepted 10 January 1984)

ePIthimum Dodder of Time, to which add common Dodder, which is usually that which grows upon flax: indeed every Dodder retains a virtue of that herb or plant it grows upon, as Dodder that grows upon Broom, provokes urine forcibly, and loosens the belly, and is moister than that which grows upon flax: That which grows upon time, is hotter and dryer than that which grows upon flax, even in the third degree, opens obstructions, helps infirmities of the spleen, purgeth melancholy, relieves drooping spirits, helps the rickets: That which grows on flax, is excellent for agues in young children, strengthens weak stomachs, purgeth choler, provokes urine, opens stoppings in the reins and bladder. That which grows upon nettles, provokes urine exceedingly. The way of using it is to boil it in white wine, or other convenient decoction, and boil it very little. (Nicholas Culpeper (1616-54) The Complete Herbal, 1850.)

AMBERGREESE is hot and dry in the second degree, I will not dispute whether it be a Gum or not: It strengthens nature much which way soever it be taken, there are but few grains usually given of it at a time: mixed with a little ointment of Orange flowers, and the temples and forehead anointed with it, it eases the pains of the head and strengthens the brain exceedingly; the same applied to the privities helps the fits of the mother; inwardly taken it strengthens the brain and memory, the heart and vital spirit, warms cold stomachs, and is an exceeding strengthener of nature to old people, adding vigour to decayed and worn-out spirits: it provokes venery, and makes barren women fruitful, if coldness and moisture or weakness be the cause impediting. (Nicholas Culpeper (1616-54) The Complete Herbal, 1850.) 